\title{
Mammalian Target of Rapamycin's Distinct Roles and Effectiveness in Promoting Compensatory Axonal Sprouting in the Injured CNS
}

\author{
Do-Hun Lee, Xueting Luo, @Benjamin J. Yungher, Eric Bray, Jae K. Lee, and Kevin K. Park \\ Miami Project to Cure Paralysis and Department of Neurosurgery, University of Miami Miller School of Medicine, Miami, Florida 33136
}

\begin{abstract}
Mammalian target of rapamycin (mTOR) functions as a master sensor of nutrients and energy, and controls protein translation and cell growth. Deletion of phosphatase and tensin homolog (PTEN) in adult CNS neurons promotes regeneration of injured axons in an mTOR-dependent manner. However, others have demonstrated mTOR-independent axon regeneration in different cell types, raising the question of how broadly mTOR regulates axonal regrowth across different systems. Here we define the role of mTOR in promoting collateral sprouting of spared axons, a key axonal remodeling mechanism by which functions are recovered after CNS injury. Using pharmacological inhibition, we demonstrate that $\mathrm{mTOR}$ is dispensable for the robust spontaneous sprouting of corticospinal tract axons seen after pyramidotomy in postnatal mice. In contrast, moderate spontaneous axonal sprouting and induced-sprouting seen under different conditions in young adult mice (i.e., PTEN deletion or degradation of chondroitin proteoglycans; CSPGs) are both reduced upon mTOR inhibition. In addition, to further determine the potency of mTOR in promoting sprouting responses, we coinactivate PTEN and CSPGs, and demonstrate that this combination leads to an additive increase in axonal sprouting compared with single treatments. Our findings reveal a developmental switch in mTOR dependency for inducing axonal sprouting, and indicate that PTEN deletion in adult neurons neither recapitulates the regrowth program of postnatal animals, nor is sufficient to completely overcome an inhibitory environment. Accordingly, exploiting mTOR levels by targeting PTEN combined with CSPG degradation represents a promising strategy to promote extensive axonal plasticity in adult mammals.
\end{abstract}

Key words: axon growth; axon regeneration; axon sprouting; mTOR; PTEN; pyramidotomy

\section{Introduction}

Following injury, axonal remodeling in the form of collateral sprouting of spared axons that compensate for lost circuits represents a key mechanism by which behavioral functions are recovered (Schwab, 2002; Weidner and Tuszynski, 2002; Fouad et al., 2011). For instance, in the case of spinal cord injury (SCI), clinical lesions are often anatomically and functionally incomplete, and thus compensatory sprouting of uninjured axons represents an important mechanism for functional recovery. Such axonal regrowth is robust after injury in postnatal animals but diminishes with age.

\footnotetext{
Received May 13, 2014; revised 0ct. 3, 2014; accepted 0ct. 6, 2014

Author contributions: J.K.L. and K.K.P. designed research; D.-H.L., X.L., B.J.Y., J.K.L., and K.K.P. performed research; E.B. and K.K.P. contributed unpublished reagents/analytic tools; D.-H.L., X.L., J.K.L., and K.K.P. analyzed data; D.-H.L., B.J.Y., J.K.L., and K.K.P. wrote the paper.

This work was supported by grants from U.S Army W81XWH-05-1-0061 (K.K.P., J.K.L.), W81XWH-12-1-0319 (K.K.P.), NIH/NEl (K.K.P.), Ziegler Foundation (K.K.P.), Pew Charitable Trust (K.K.P.), Craig H. Neilsen Foundation (K.K.P., D.H.L., J.K.L.), and the Buoniconti Fund (K.K.P., J.K.L.). We thank the Imaging Core and Viral Vector Core at the Miami Project to Cure Paralysis, Dr Fan Wang (Duke University) for Rosa26 flox-stop-flox tdTomato mice, Dr Veronica J. Tom (Drexel University) for advice on experiment involving CSPGs and chABC, and Yadira Salgueiro for assisting with genotyping and histology.

The authors declare no competing financial interests.

Correspondence should be addressed to either Dr Kevin K. Park or Jae K. Lee, Miami Project to Cure Paralysis, University of Miami, Miller School of Medicine, Miami, FL, 33136, E-mail: kpark@med.miami.edu or JLee22@med.miami.edu.

DOI:10.1523/JNEUROSCI.1935-14.2014

Copyright $\odot 2014$ the authors $\quad 0270-6474 / 14 / 3415347-09 \$ 15.00 / 0$
}

Mammalian target of rapamycin (mTOR) is a protein kinase that controls ribosome biogenesis and protein translation (Laplante and Sabatini, 2012). The level of mTOR activity in CNS neurons declines during development (Park et al., 2008), correlating with the decrease in their regrowth ability. We and others have demonstrated that deletion of phosphatase and tensin homolog (PTEN) or tuberous sclerosis proteins $1 / 2$ in several different types of CNS neurons enhances axonal regeneration, an effect inhibited by mTOR blockade (Park et al., 2008; Abe et al., 2010; Byrne et al., 2014). In contrast, others have reported minimal roles of mTOR in promoting axon regeneration in sensory neurons (Christie et al., 2010), indicating that neurons under different conditions may employ mTOR-dependent or independent mechanisms to trigger axonal regrowth. Overall, although the role of $\mathrm{mTOR}$ in regulating regeneration of injured axons has been extensively studied, whether mTOR plays a general role in promoting axonal remodeling by compensatory sprouting of uninjured axons is unclear.

The aims of the present study were twofold. Using a pyramidotomy model in which one side of corticospinal tract (CST) is severed; first, we examined the loss of mTOR function in regulating compensatory sprouting of intact CST axons in postnatal animals and in young adult animals under different growth promoting conditions. Second, we assessed whether coupling PTEN/mTOR modulation with degradation of chondroitin proteoglycans (CSPGs), a 

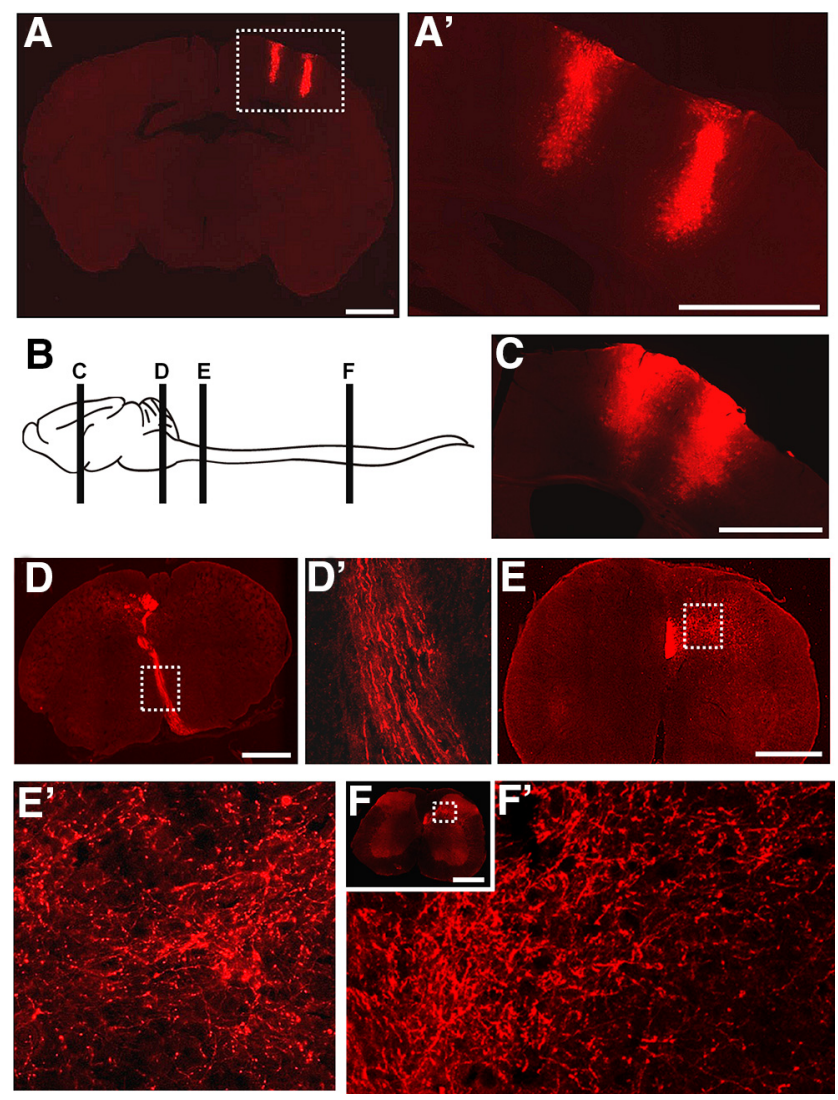

Figure 1. AAV-Cre-mediated labeling of CST axons in Rosa26-tdTomato reporter mice. $\boldsymbol{A}$, Coronal brain section of Rosa-tdTomato reporter mouse shows tdTomato ${ }^{+}$cortical neurons as early as 1 week after AAV-Cre injection $(n=3) . \boldsymbol{A}^{\prime}$, Higher-magnification of the boxed areas in $\boldsymbol{A}$. Schematic representation showing the transverse planes at which the images $(\boldsymbol{C}-\boldsymbol{F})$ are found in mouse brain and spinal cord. At 2 weeks following intracortical AAV-Cre injection in the Rosa26 reporter mice, tdTomato-labeled axons are seen in $(\boldsymbol{C})$ motor cortex, $(\boldsymbol{D})$ brainstem at the level of CST decussation, $(\boldsymbol{E})$ cervical spinal cord, and $(\boldsymbol{F})$ lumbar spinal cord. $\boldsymbol{D}^{\prime}$, Highermagnification of the boxed areas in $\boldsymbol{D}$. $\boldsymbol{F}$, Low-magnification image of the coronal section at the lumbar level. $\boldsymbol{F}^{\prime}$, Higher-magnification of the boxed areas in $\boldsymbol{F}$. Scale bars: $\boldsymbol{A}, \boldsymbol{C}, 1000 \mu \mathrm{m} ; \boldsymbol{D}-\boldsymbol{F}$, $500 \mu \mathrm{m}$.

potent extrinsic inhibitor of axon regrowth (Davies et al., 1997; Bradbury et al., 2002; Barritt et al., 2006; Crespo et al., 2007; Kwok et al., 2008; Harris et al., 2010; Lee et al., 2010a; Jefferson et al., 2011; Zhao et al., 2011; Takeuchi et al., 2013) enhances sprouting in an additive or synergistic manner.

\section{Materials and Methods}

Animals. All experimental procedures were performed in compliance with protocols approved by the IACUC at University of Miami. Animals used were C57BL/6, PTEN ${ }^{f / f}$ mice (The Jackson Laboratory; 006440), Rosa26 loxP-stop-loxP-tdTomato (Rosa-tdTomato; a generous gift from Dr Fan Wang, Duke University) and $P T E N^{f / f} ;$ Rosa-tdTomato.

$A A V$ preparation. For making adeno-associated viruses (AAVs), the cDNA of Cre was inserted downstream of the CMV promoter/ $\beta$-globin intron enhancer in the plasmid pAAV-MCS (Stratagene), containing the AAV serotype-2 (AAV2) inverted terminal repeats and a human growth hormone polyA signal. pAAV-RC (Stratagene) that encodes the AAV2 genes (rep and cap) and the helper plasmid (Stratagene) that encodes E2A, E4, and VA were used for cotransfection in 293T cells to generate recombinant AAV. Plasmids were then used to produce AAV2 $(1-4 \times$ $10^{13}$ particles $/ \mathrm{ml}$ ) at the University of Miami Viral Vector Core.

$A A V$ injection and BDA labeling. Female PTEN ${ }^{f / f} ;$ Rosa-tdTomato or Rosa-tdTomato mice aged 4-5 weeks were anesthetized with ketamine/ xylazine (100 mg/15 mg/kg, i.p) and injected with a total of 1-2 $\mu \mathrm{l} \mathrm{AAV}$ into the left sensorimotor cortex at the following six sites: 0.5 and $0.1 \mathrm{~mm}$ anterior, and $0.3 \mathrm{~mm}$ posterior; 1.2 and $2.2 \mathrm{~mm}$ lateral (in reference to bregma). To label CST axons using biotinylated dextran amines (BDA), $1-2 \mu l$ of BDA ( $10 \%$, Invitrogen) was injected into sensorimotor cortex 2 weeks before euthanasia (Lee et al., 2010b).

Pyramidotomy. For pyramidotomy, mice were anesthetized with ketamine/xylazine. The procedure is similar to that described previously (Lee et al., 2010b; Liu et al., 2010). Following craniotomy of the occipital bone using laminectomy forceps to expose the underlying pyramidal tract of mice (Starkey et al., 2005), a micro feather scalpel was used to puncture the dura and lesion the entire right pyramidal tract.

$C h A B C$ delivery. Immediately after pyramidotomy, mice received either $6 \mu$ l protease-free Chondroitinase $\mathrm{ABC}(\mathrm{ChABC}$; Sigma-Aldrich; 10 $\mathrm{U} / \mathrm{ml}$ in saline) followed by a $3 \mu \mathrm{l}$ saline flush, delivered as a bolus injection via the intracerebroventricular cannula tubing as described previously (Starkey et al., 2012). Control-treated mice were treated with vehicle ( $9 \mu$ l of saline). Further injections were performed on days 2, 4, 6 , 8 , and 10 following pyramidotomy. Briefly, the skull was exposed and a hole made with a 25 gauge needle at the following coordinates: -0.5 from bregma, $1 \mathrm{~mm}$ lateral to the midline. An intracerebroventricular cannula (Alzet) was inserted into the hole and secured into place using super glue (Loctite). The skin was then sutured over the cannula leaving the tubing exposed.

Rapamycin administration. Rapamycin was obtained from LC Laboratories, dissolved at $20 \mathrm{mg} / \mathrm{ml}$ in ethanol. Before each administration, rapamycin was diluted in 5\% Tween $80,5 \%$ polyethylene glycol 400 $(0.5-1.5 \mathrm{mg} / \mathrm{ml})$. Rapamycin at $6 \mathrm{mg} / \mathrm{kg}$ or the vehicle was given intraperitoneally on the day of pyramidotomy and every third day until euthanasia.

Tissue processing and immunohistochemistry. Tissue processing and immunohistochemical procedures were performed as described previously (Liu et al., 2010; Sun et al., 2011). Mice were killed and transcardially perfused with $4 \%$ paraformaldehyde. Tissues were isolated and postfixed in the same fixative overnight at $4^{\circ} \mathrm{C}$. Tissues were cryoprotected in $30 \%$ sucrose and serial sections $(16-25 \mu \mathrm{m})$ were collected. To detect BDA labeled fibers, coronal sections were washed in PBS and detected with streptavidin-AlexaFluor 594 (Invitrogen). To detect tdTomato signal, sections were immunostained overnight at $4^{\circ} \mathrm{C}$ with rabbit red fluorescent protein antibody (RFP; 1:200 dilution; Rockland). Other antibodies used were rabbit p-S6 (1:200 dilution; S235-236; Cell Signaling Technology), Mouse NeuN (1:500 dilution; Millipore), and rabbit PTEN (1:200 dilution; CST).

Assessment of lesion and CSPG degradation. Cryosections from spinal cord $10 \mathrm{~d}$ after pyramidotomy were incubated with anti-C-4-S (ICN) followed by incubation with secondary antibody (Jackson ImmunoResearch; Starkey et al., 2012). To determine the degree of unilateral pyramidotomy, sections from spinal cord at 4 weeks after injury was immunostained with an antibody against PKC- $\gamma$ (1:50 dilution; Santa Cruz Biotechnology; Starkey et al., 2012).

Axon counting. For quantifying total labeled CST axons, axons were manually counted at the level of medulla oblongata proximal to the pyramidal decussation. Axons were counted in four rectangular areas randomly placed in the pyramidal tract and this axon density was multiplied by the total area of the tract to obtain the total number of labeled axons. This was done for two sections placed $160 \mu \mathrm{m}$ apart and then the two counts were averaged to obtain the final number for each animal. To count the sprouted axons, two vertical lines, adjacent and $500 \mu \mathrm{m}$ lateral to the central canal were drawn, and fibers crossing each line were manually counted in each section. The results were presented after normalization with the number of counted CST fibers at the medulla level: sprouting axon number index is represented as the ratio of the total number of sprouted axons in the denervated spinal cord over the number of labeled axons at the level of medulla. At least three sections were counted for each animal and averaged together.

The numbers of animals used for quantifying the degree of axonal sprouting. Animals with profound lack of tdTomato labeling in the cortex and medulla (1-2 animals per group), most likely due to injection errors were excluded from analysis. For the final quantification in Figure 4, the numbers of animals used per group are as follows: 8 (for "sham," "Px+rapamycin," "Px+PTEN KO+rapamycin" and 
A
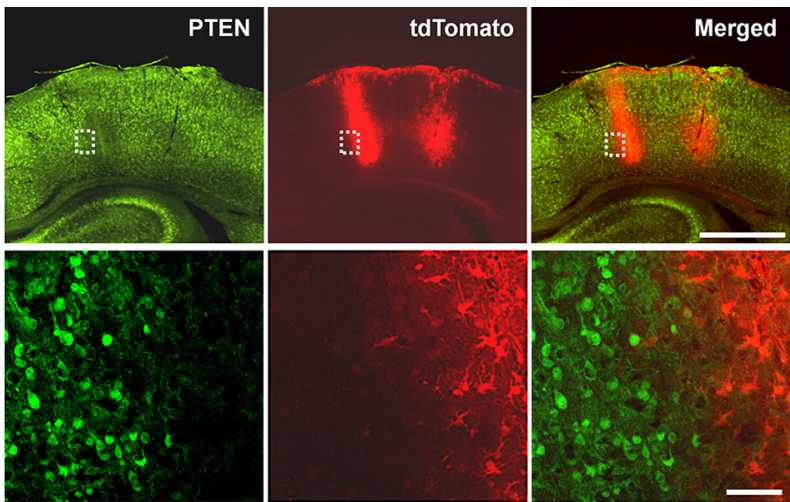

B
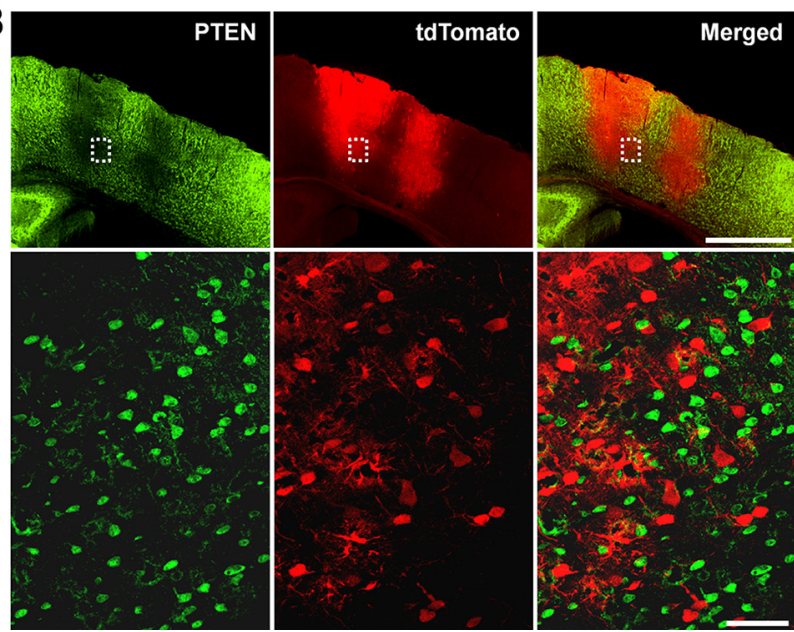

Figure 2. Concomitant PTEN deletion and axonal labeling in PTEN $N^{f f f} ;$ Rosa26-tdTomato mice. Sensorimotor cortex of $P$ TEN $^{\mathrm{fff}}$; Rosa-tdTomato mice, at $1(\boldsymbol{A})$ and $2(\boldsymbol{B})$ weeks after AAV-Cre injection. PTEN is depleted in tdTomato-expressing neurons as early as 1 week after AAV-Cre injection $(n=3)$. Coronal sections were immunostained with antibodies against PTEN (green) and RFP (red). $A$, Bottom, Higher-magnification of the boxed areas above. $\boldsymbol{B}$, Bottom, Higher-magnification of the boxed areas above. Scale bars: (top) $\boldsymbol{A}, \boldsymbol{B}$, $1000 \mu \mathrm{m}$; (bottom) $\boldsymbol{A}, \boldsymbol{B}, 100 \mu \mathrm{m}$.

"Px + ChABC + rapamycin"), 10 (for "Px only"), and 13 (for "Px + PTEN $\mathrm{KO}+$ rapamycin). For the quantification in Figure 7, the numbers of animals used per group are as follows: 7 (for "sham" and "Px only"), 8 (for "Px+rapamycin"), and 9 (for "sham + rapamycin). For the quantification in Figure 8, the numbers of animals used per group are as follows: 8 (for "Px+PTEN KO"), 10 (for "Px only" and "Px+ChABC"), and 12 (for "Px + PTEN KO+ChABC").

Statistics. GraphPad Prism software was used for statistical analyses. Values were calculated as mean + SEM. For sprouting axon number index, two-way repeated-measures ANOVA was used, followed by Bonferroni post hoc test. Values of $p<0.05$ were considered significant.

\section{Results}

Assessment of PTEN deletion-induced axonal regrowth in Rosa26-tdTomato reporter mice

Recent studies have identified several neuron intrinsic factors that limit axon regeneration. For instance, AAV-Cre-mediated PTEN deletion in neonatal animals followed by pyramidotomy in young adults resulted in enhanced axonal sprouting (Liu et al., 2010). We sought to further define the effects of PTEN deletion and the role of its key downstream effector mTOR in axonal sprouting responses. In the previous study, $P T E N^{f / f}$ mice received AAV-Cre injection into sensorimotor cortex, followed by BDA injections several weeks later (Liu et al., 2010). However, even multiple BDA injections were only able to label axons in $20-50 \%$
A
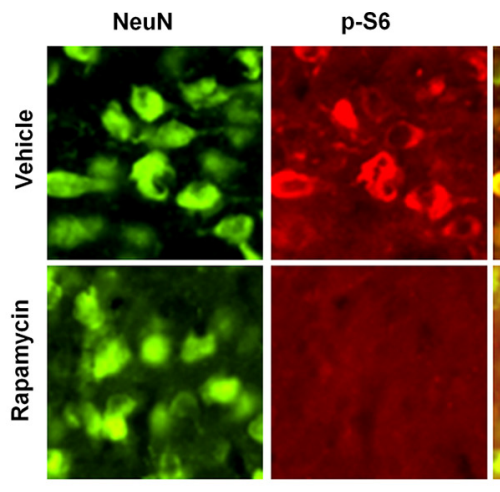

Merged

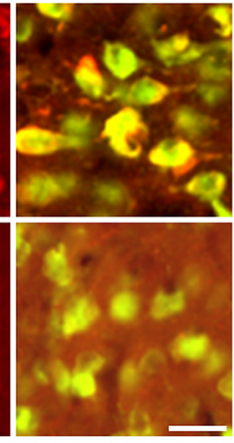

B
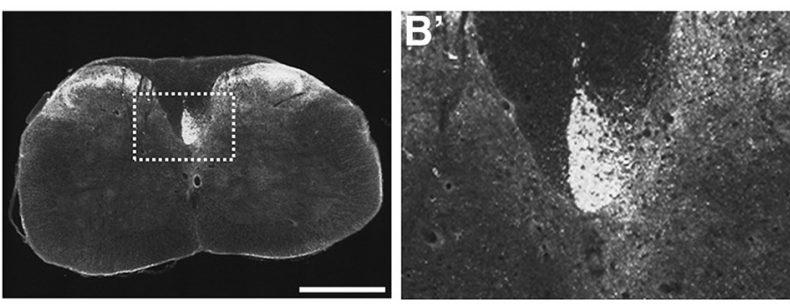

Saline treated
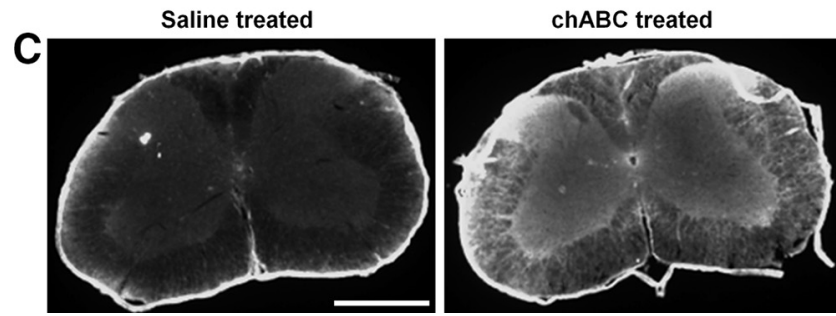

Figure 3. Validation of the lesion, levels of mTOR activity and CSPG degradation in pyramidotomy model. $A$, Representative coronal sections of PTEN ${ }^{f / f} ;$ Rosa-tdTomato motor cortex stained with $\mathrm{p}-\mathrm{S} 6$ and NeuN antibodies show depletion of p-S6 immunoreactivity in cortical neurons following rapamycin treatment. Rapamycin or vehicle was administered every third day, starting from the day of pyramidotomy and animals were perfused 4 weeks after injury. $\boldsymbol{B}$, Representative coronal section of cervical spinal cord showing absence of PKC- $\gamma$ immunoreactivity in the transected CST tract $(n=8)$. $\boldsymbol{B}^{\prime}$, Highermagnification of the boxed area in $B$. C, C-4-S immunostaining to validate CSPG digestion in the cervical spinal cord $(n=3)$. Scale bars: $A, 25 \mu \mathrm{m} ; \boldsymbol{B}, \boldsymbol{C}, 500 \mu \mathrm{m}$.

of PTEN deleted-neurons (data not shown), thus limiting faithful assessment of PTEN-deletion effects. To study axonal phenotype specifically in PTEN-deleted neurons, we tested AAV-Cre that also expresses enhanced green florescent protein (EGFP), which can be used to label axons in place of dye tracers. However, EGFP labeling was weak in terms of both the number of labeled axons and signal intensity (data not shown). Alternatively, we crossed $P T E N^{f / f}$ mice with Rosa-tdTomato to generate $P$ TEN ${ }^{f / f} ;$ Rosa-tdTomato mice, allowing simultaneous gene deletion and axon labeling via Cre-mediated recombination. Because even very low expression of Cre is sufficient to recombine lox sites, AAV-Cre should yield efficient axon labeling. Indeed, injections of AAV-Cre into the cortex of RosatdTomato or $P T E N^{f / f}$;Rosa-tdTomato mice led to transduction of cortical cells as revealed by Tdtomato immunostaining as early as $7 \mathrm{~d}$ after injection (Fig. $1 A$ ) and, importantly, efficient labeling of the CST in the brain and spinal cord by 2 weeks (Fig. $1 B-F$ ). In $P T E N^{f / f}$;Rosa-tdTomato mice, immunohistochemistry performed at 7 and $14 \mathrm{~d}$ after AAV-Cre injection shows deletion of PTEN in tdTomato-expressing cells in the cortex (Figs. $2 A, B$ ). 

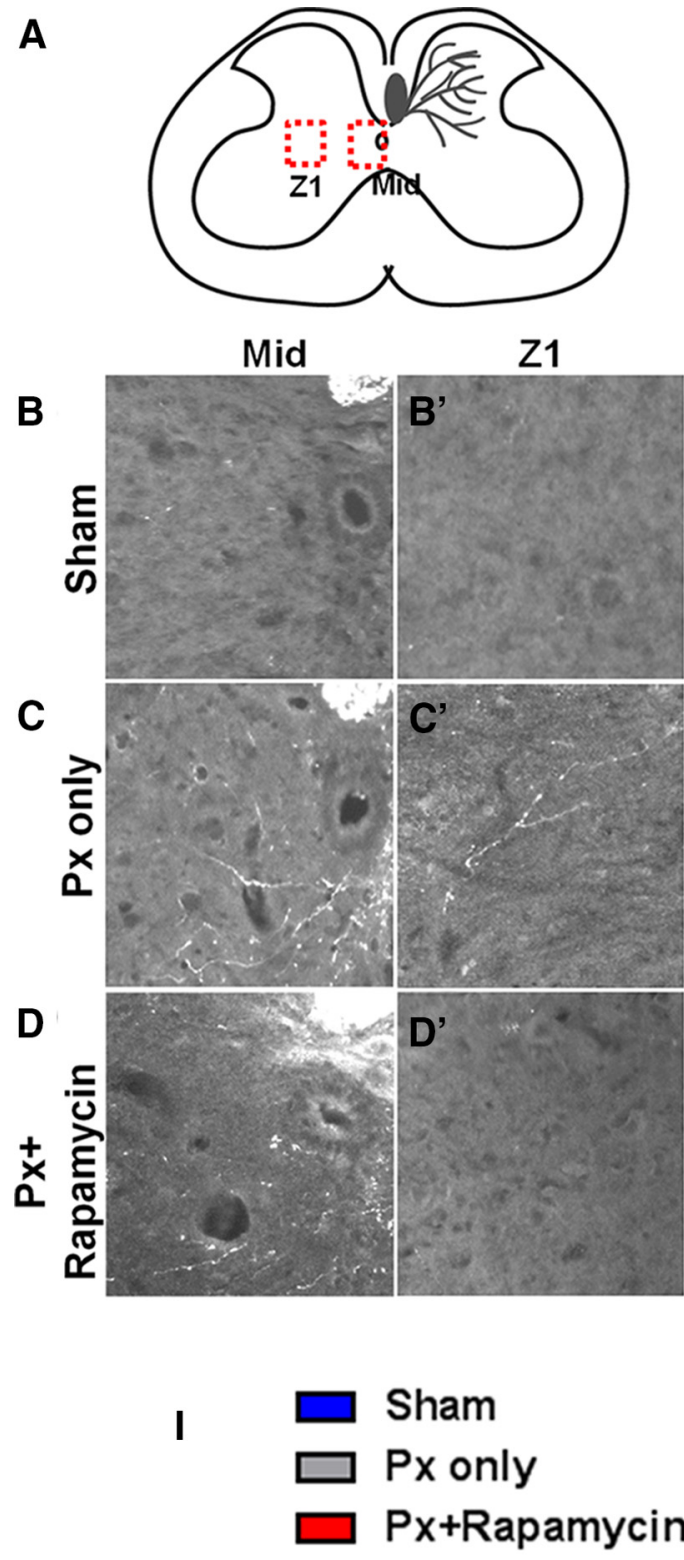
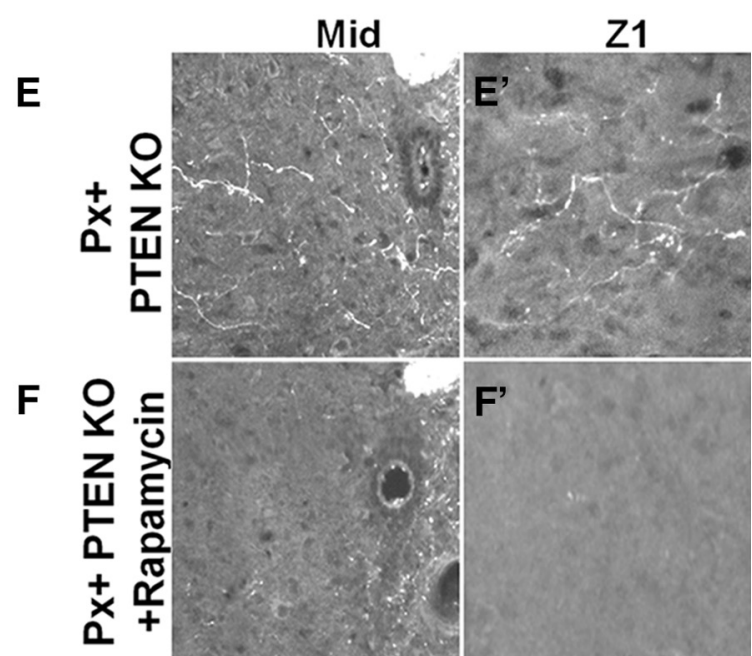

G

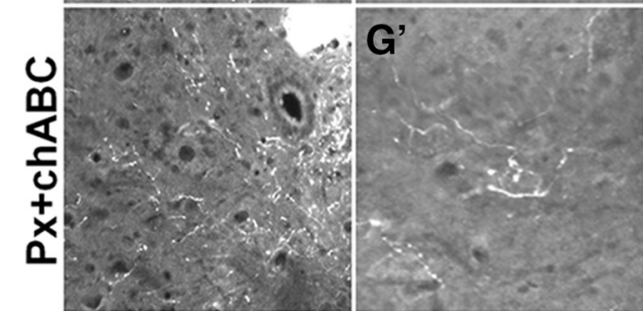

H

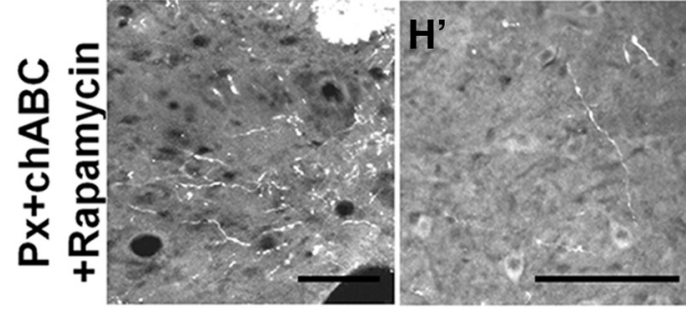

$P X+P T E N K O$

PX+PTEN KO+Rapamycin

$P x+c h A B C$

$P x+c h A B C+R a p a m y c i n$

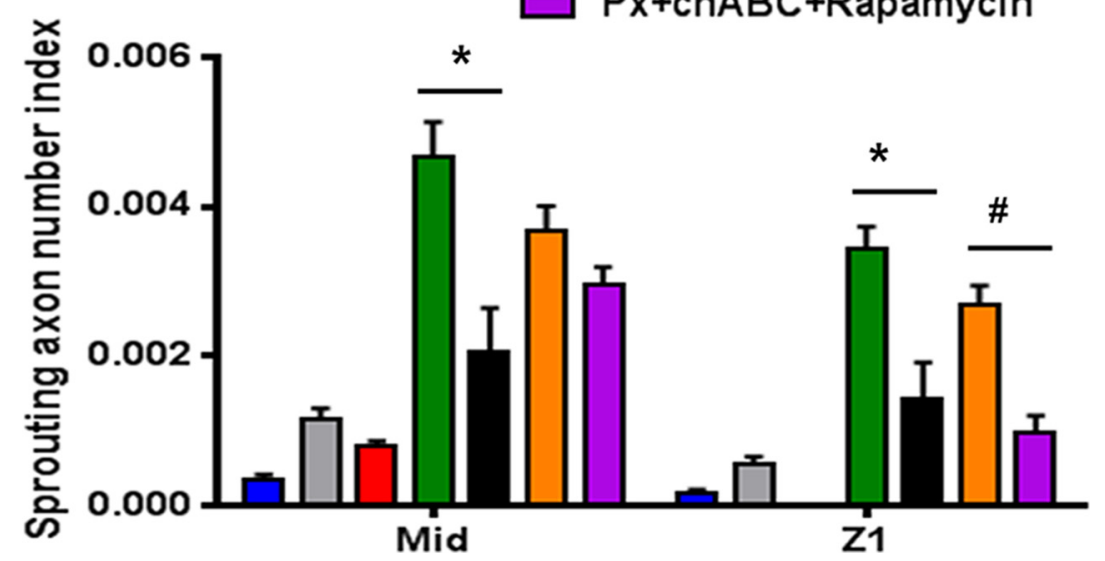

Figure 4. Axonal sprouting and mTOR dependency in young adult mice. $\boldsymbol{A}$, Schematic representation of spinal cord section showing two areas (Mid and Z1) where vertical lines were drawn, and crossing axons were counted. $\boldsymbol{B}-\boldsymbol{H}$, Representative of $\left(5\right.$ coronal sections, enlarged midline $(\boldsymbol{B}-\boldsymbol{H})$ or $Z \mathbf{Z}\left(\boldsymbol{B}^{\prime}-\boldsymbol{H}^{\prime}\right)$ regions from sham-operated Rosa-tdTomato (sham), pyramidotomized Rosa-tdTomato (Px only), pyramidotomized PTEN ${ }^{f / f}$ Rosa-tdTomato with vehicle (Px+PTEN K0), or with rapamycin (Px+PTEN K0+Rap), and pyramidotomized Rosa-tdTomato-ChABC mice with vehicle (Px+ChABC) or rapamycin (Px+ChABC+Rapamycin); $n=8-13 /$ group. I, Quantifications of crossing axons counted in different regions normalized against the numbers of labeled CST axons in sham-operated Rosa-tdTomato (sham), pyramidotomized Rosa-tdTomato (Px only), pyramidotomized PTEN ${ }^{f / f}$ Rosa-tdTomato with vehicle (Px+PTEN K0) or with rapamycin (Px+PTEN KO+Rap), and pyramidotomized Rosa-tdTomato-ChABC mice with vehicle (Px+ChABC) or rapamycin (Px + ChAB + Rapamycin); ${ }^{*} p<0.001 ; \# p<0.05$, two-way repeat measures ANOVA followed by Bonferroni post-test. Error bars indicate SEM; $n=8-13 /$ group. Scale bar, $100 \mu m$. 
A
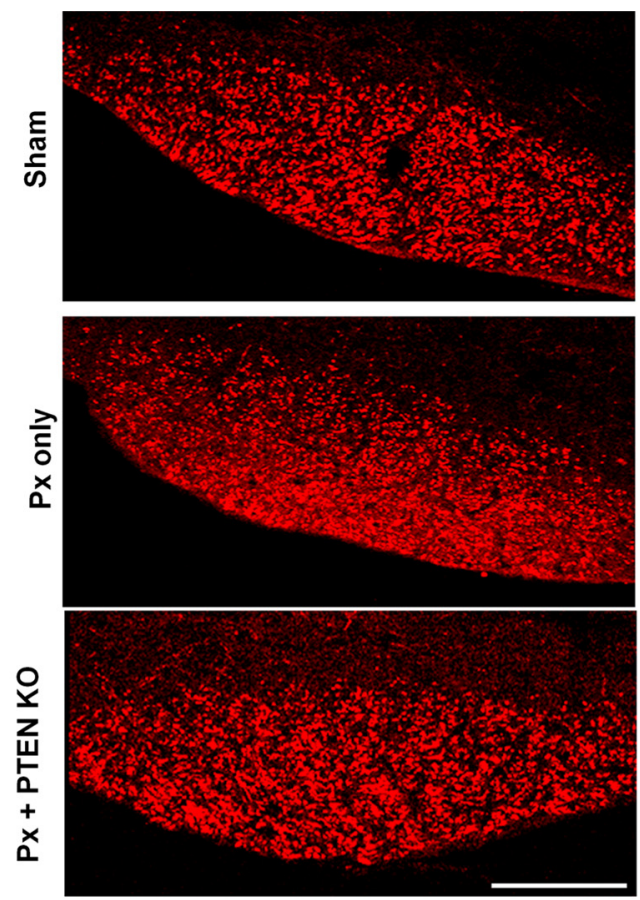

B

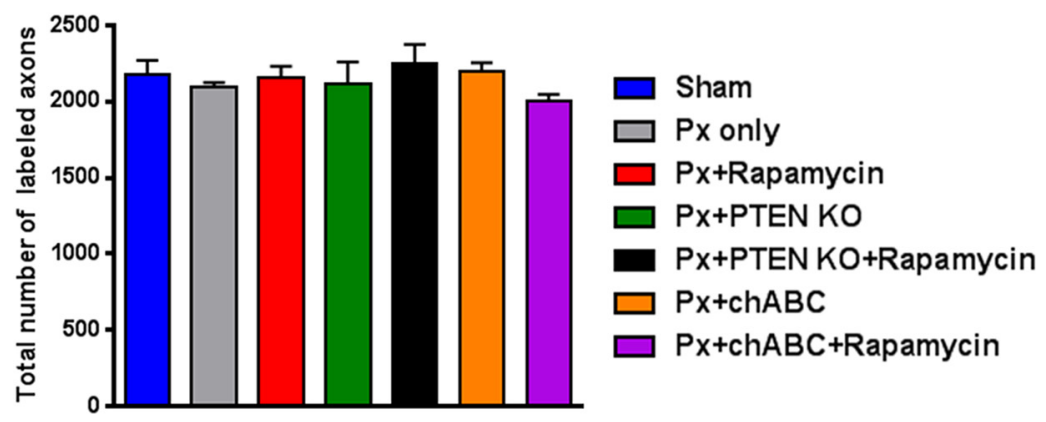

Figure 5. Degree of tdTomato labeling at the level of medulla in various animal groups. $\boldsymbol{A}$, Representative coronal sections of the medullary pyramid showing tdTomato labeled-CST axons 5 weeks after AAV-Cre injection (i.e., 4 weeks after pyramidotomy) in sham-operated Rosa-tdTomato (sham), pyramidotomized Rosa-tdTomato (Px only), and pyramidotomized PTEN ${ }^{f / f}$ Rosa-tdTomato (Px+PTEN KO) mice. $\boldsymbol{B}$, Quantification of total tdTomato labeled-CST axons at the medullary pyramid in each animal groups. Error bars indicate SEM. Px, Pyramidotomy. Scale bars, $100 \mu \mathrm{m}$.

\section{Axonal sprouting and mTOR-dependency in young adult mice}

We set out to determine whether PTEN deletion in CST neurons of young adult mice (4-5 weeks of age) enhances compensatory sprouting, and if so, whether mTOR is required. PTEN ${ }^{f / f}$;RosatdTomato, or Rosa-tdTomato mice received AAV-Cre injection, followed by unilateral pyramidotomy 1 week later. Some of these animals also received rapamycin treatment to block mTOR activity. Rapamycin's efficacy in inhibiting mTOR in cortical neurons was validated by the decrease in $\mathrm{p}-\mathrm{S} 6$ immunoreactivity, a commonly used marker of mTOR activity (Fig. $3 A$ ). The completeness of lesion was assessed by the degree of loss of PKC $\gamma$ immunostaining in the lesioned CST tract (Lee et al., 2010b; Starkey et al., 2012). We find that the lesion results in drastic loss of PKC $\gamma$, confirming the severity of pyramidotomy (Fig. $3 B$ ). As assessed by immunofluorescent visualization of tdTomato labeled-axons 4 weeks after injury, PTEN deletion elicited significant increase in trans-midline sprouting of CST axons from the intact side into the denervated side compared with the wild-type injured mice
(Figs. 4A-I). Thus, these results extend the previous study (Liu et al., 2010; in which PTEN was deleted in neonatal animals) to show that PTEN deletion in young adult mice is also sufficient to enhance axonal sprouting. Furthermore, we found that inhibition of mTOR in cortical neurons via rapamycin treatment significantly inhibited sprouting in PTEN KO mice; at two different distances (i.e., Mid and $\mathrm{Z1}$ ) away from the central canal, sprouting was markedly reduced in mTOR-inhibited animals (Figs. 4A-I). The total numbers of tdTomato-labeled axons in the brainstem at the level of medullar oblongata were similar among the different animal groups (Figs. $5 A, B$ ), indicating that rapamycin treatment per se does not affect the degree of axonal labeling, and that differences in sprouting axon number was not due to differences in axon labeling efficiency. Overall, these data indicate that mTOR is critically involved in promoting axonal sprouting in PTEN KO animals.

We observed that pyramidotomy per se in young adult mice also increases sprouting compared with sham-operated animals (Figs. 4A-I), indicating that CST neurons at this age possess some degree of sprouting capacity Baseline mTOR activity is detected in the young adult CST neurons (Fig. 6A). Thus, we examined whether endogenous mTOR is required for the spontaneous sprouting. Indeed, mTOR inhibition reduced the spontaneous sprouting in the young adults; the extent of reduction was more drastic in the areas distant (i.e., $\mathrm{Z1}$ ) to the midline (Figs. $4 A-I)$.

Inactivation of CSPGs has been shown to enhance axonal regrowth after SCI (Cafferty et al., 2007; Tom et al., 2009; Lee et al., 2010a; Alilain et al., 2011; Zhao et al., 2011; Starkey et al., 2012; Takeuchi et al., 2013). We also examined whether mTOR is required for enhanced sprouting in CSPG-inactivated animals, without PTEN deletion. To this end, Rosa-tdTomato mice received AAV-Cre injection and intracerebroventricular delivery of ChABC, an enzyme that degrades the inhibitory glycosaminoglycan side-chains. To validate CSPG digestion, tissues were immunostained with anti-C-4-S antibody, which detects digested disaccharide "stubs" but not the intact chondroitin sulfate. ChABC led to intense C-4-S immunofluorescence in the cervical spinal cord of animals with unilateral lesion while no obvious signal was evident in animals with saline treatment (Fig. 3C), confirming CSPG degradation. Consistent with the previous report (Starkey et al., 2012), ChABC enhanced sprouting of intact CST axons after pyramidotomy compared with the animals receiving pyramidotomy and intracerebroventricular delivery of saline (Figs. $4 A-I$ ). Inhibition of mTOR led to a small reduction in the number of sprouting axons at the "Mid" area close to the midline in ChABC animals. A more drastic re- 
duction was found at the " $\mathrm{Z1}$ " area distal to the midline (Figs. $4 A-I$ ).

mTOR is dispensable for compensatory sprouting of CST axons in postnatal mice

Consistent with the idea that mTOR correlates with neurons' capacity to regrow axons, mTOR activity is high in postnatal day (P)7 cortical neurons compared with young adult mice (Fig. 6A). A previous study has reported that a unilateral pyramidotomy given at $\mathrm{P} 7$ mice results in extensive spontaneous sprouting of CST axons (Liu et al., 2010). Next, we examined whether mTOR is also involved in this form of sprouting in postnatal animals. Similar to that seen in young adult mice, phospho-S6 immunoreactivity shows effective blockade of mTOR after rapamycin treatment in the layer $\mathrm{V}$ neurons (Fig. $6 B)$. Importantly, the total numbers of labeled axons in the brainstem at the level of medullar oblongata were similar among the different animal groups (data not shown). Consistent with the previous report (Liu et al., 2010), we observed extensive axonal spouting 4 weeks after injury in animals receiving pyramidotomy at $\mathrm{P} 7$, (Figs. 7A-E). Interestingly, despite mTOR inhibition, the degree of sprouting was not affected compared with pyramidotomyonly animals. In fact, we observed more sprouting in rapamycin-treated animals, though this increase was not statistically significant (Figs. $7 A-E$ ). Together, these data indicate that $\mathrm{mTOR}$ is not required for extensive compensatory axonal sprouting in postnatal animals.

\section{Coinactivation of PTEN and CSPGs additively enhances axonal sprouting}

Our results show that immature neurons spontaneously mount robust sprouting responses regardless of mTOR level. In adult animals however, robust sprouting likely require comodulating multiple neuron intrinsic pathways (i.e., PTEN/mTOR and others). Alternatively, comodulating PTEN/mTOR and environmental inhibitors may yield greater effects. To examine the effects of coinactivating PTEN and CSPGs, we generated $P T E N^{f / f}$;Rosa-tdTomato mice receiving both AAV-Cre and ChABC. This cotreatment (i.e., PTEN $\mathrm{KO} / \mathrm{ChABC}$ ) led to marked increases in the number of sprouting axons compared with either treatment alone; at 4 weeks after pyramidotomy, there was $\sim 2$-fold increase in the number of Tdtomatolabeled sprouting axons in the PTEN KO/ChABC group compared with either single treatment groups, indicating additive effects by targeting both PTEN and CSPGs (Figs. $8 A-E$ ). Furthermore, we observed that many of the tdTomato-labeled sprouting axons in the PTEN KO/ChABC animals that are in close contact with the motor neurons colocalize with presynaptic marker, Vglut 1 (Figs. $8 F, G$ ), suggesting that newly formed collaterals in PTEN KO/ChABC animals are capable of forming synapses in the denervated spinal cord.
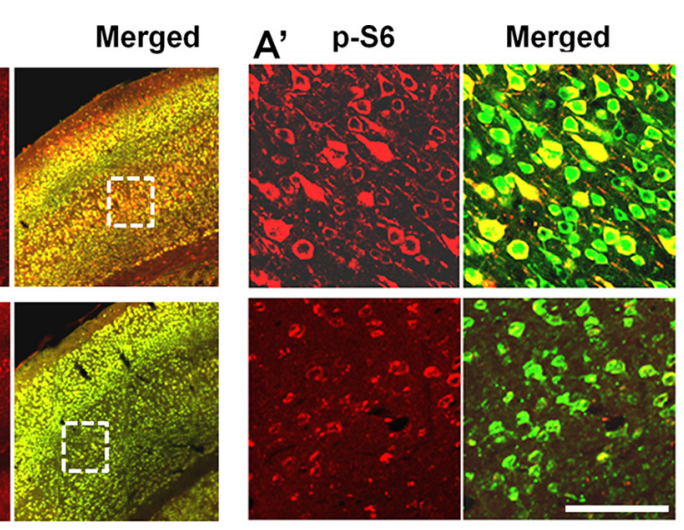

NeuN
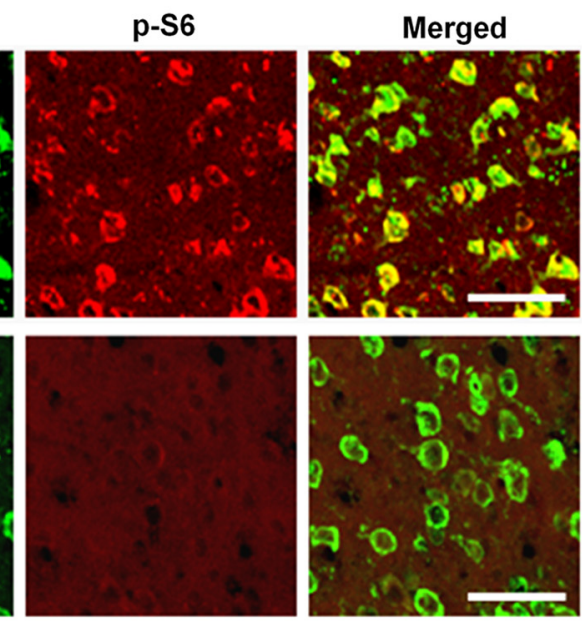

8
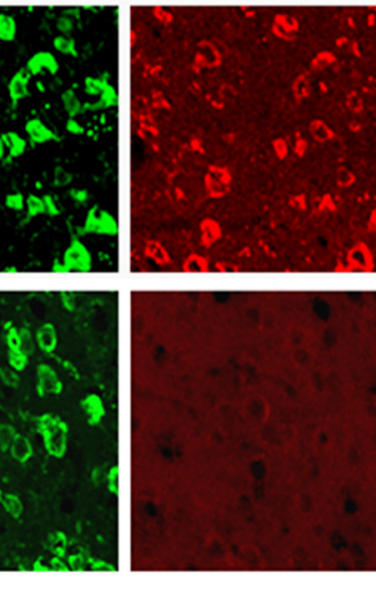

Figure 6. The level of cortical mTOR activity in postnatal, young adult mice and after postnatal rapamycin treatment. $\boldsymbol{A}$, Representative coronal sections of motor cortex from P7 and P35 mice stained with p-S6 and NeuN antibodies. $\boldsymbol{A}^{\prime}$, Higher$\mathrm{p}$-S6 and NeuN antibodies. Animals received either vehicle or rapamycin treatment and were perfused at 4 weeks after pyramidotomy. Scale bars: $\boldsymbol{A}, 500 \mu \mathrm{m} ; \boldsymbol{A}^{\prime}, 100 \mu \mathrm{m} ; \boldsymbol{B}, 50 \mu \mathrm{m}$.

\section{Discussion}

Due to its function as a master sensor that integrates extracellular signal to regulate protein synthesis, enhanced regeneration seen after neuronal overactivation of mTOR has been attributed partly to enhanced protein translation and efficient provision of building materials required for new axons. While several studies have elicited the function of $\mathrm{mTOR}$ in promoting long distance regeneration of transected axons, whether mTOR is also involved in compensatory axonal rearrangement after injury remained unclear. Overall, we observed that young adult mice are more dependent on mTOR than postnatal animals. In postnatal stage, neurons may be capable of compensating for the loss of mTOR by triggering multiple signaling pathways relevant to axonal growth, and in promoting axonal sprouting. Both mTORdependent and -independent mechanisms of axon regeneration have been demonstrated in previous studies (Christie et al., 2010) where regeneration induced by cytokines relied on JAK/STAT3 but not on mTOR pathway (Sun et al., 2011). Therefore, mTOR, STAT3, and other signaling pathways relevant to axonal growth may be highly active in immature neurons, but not in the adult neurons (Lang et al., 2013) and facilitate sprouting. Of note, whereas short distance sprouting close to the midline is modestly reduced by mTOR inhibition, the lengthy sprouted axons normally seen in areas distant to the midline are eliminated in many animals, indicating that mTOR may play a partial role in initiating early growth responses but a more central role in sustained 

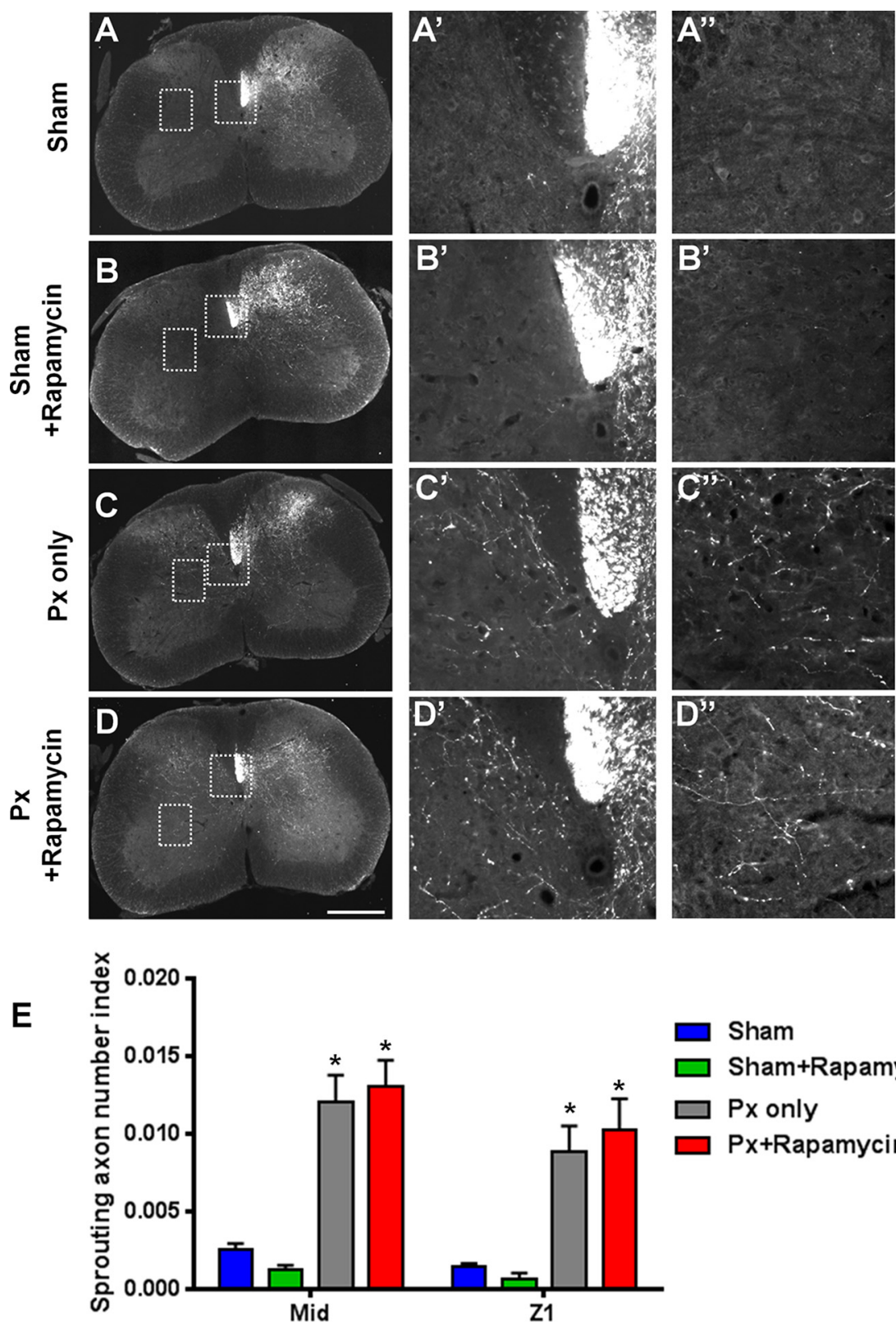

Figure 7. $\mathrm{mTOR}$ is dispensable for collateral axonal sprouting following CNS injury in postnatal mice. $\boldsymbol{A}-\boldsymbol{D}$, Representative $C 5$ coronal sections, enlarged midline $\left(\boldsymbol{A}^{\prime}-\boldsymbol{D}^{\prime}\right)$ or $Z 1\left(\boldsymbol{A}^{\prime \prime}-\boldsymbol{D}^{\prime \prime}\right)$ from sham and P7 pyramidotomy groups with vehicle or rapamycin treatment. BDA was injected into motor cortex 2 weeks before euthanasia. $\boldsymbol{E}$, Quantifications of crossing axons counted in different regions normalized against the numbers of labeled CST axons ( $n=7-9 /$ group). Asterisk indicates significantly different to the "sham" group; $p<0.0001$, two-way repeated-measures ANOVA followed by Bonferroni post-test. Error bars indicate SEM. PX, Pyramidotomy. Scale bar, $500 \mu \mathrm{m}$.

axonal elongation. Such distinct requirements for mTOR in different stages of axonal growth (axonal initiation vs elongation) has been reported previously in retinal neurons (Leibinger et al., 2012). There is also the possibility that the uncrossed CST running in the ipsilateral white matter may contribute to the axonal sprouting in the $\mathrm{Z} 1$ area. Thus, an alternative explanation is that the effect of rapamycin on reducing sprouting in the $\mathrm{Z} 1$ region after pyramidotomy and ChABC treatment may be due to its effect on the uncrossed dorsolateral CST axons innervating this region.

We note that systemic rapamycin treatment would have had global effects and inhibit mTOR activity in cell types other than CST neurons including other CNS neurons, as well as glial cells and therefore, the impact on sprouting could be attributed to non-cell autonomous effects. Interestingly, systemic rapamycin treatment has shown previously to induce neuroprotection and improved functional recovery after contusive SCI (Kanno et al., 2012; Chen et al., 2013). Thus, mTOR may mediate different biological functions in different cell types to influence pathophysiology after SCI. In the context of axonal plasticity, we find that mTOR inhibition in young adults has an adverse impact on sprouting responses. Given that systemic administration of rapamycin could potentially exert cytotoxic effects (Law, 2005), there is a possibility that the reduction in axonal sprouting seen in young adult mice may be due to reduced cell viability and axonal transport of tdTomato. However, this is unlikely because we observed no obvious neuronal death in the motor cortex of rapamycin-treated animals. Furthermore, the total numbers of labeled axons in rapamycin-treated animals were similar to that of vehicle-treated animals, indicating that the rapamycin treatment does not diminish axonal labeling. Importantly, in postnatal animals, rapamycin treatment did not reduce the degree of axonal sprouting, further indicating that rapamycin's potential toxicity does not contribute to reduction seen in the young adult animals.

Studies in the past have used AAV vectors to label regrowing axons in place of dyes (Yip et al., 2010; Blackmore et al., 2012). In this present study, we took advantage of AAV-Cre-mediated recombination in Rosa26 reporter mice for labeling axons, thus obviating the need for subsequent labeling with anterograde dyes. Given that injections of dyes can only label a portion of CST neurons that are infected previously with AAV vectors, and the sensitive nature of Cre recombination, the use of reporter mice should allow more precise assessment of PTEN deletion effects than dye tracers. However, we observed that the tdTomato signal in axons made them appear much thinner compared with what we have typically observed using BDA, and the number of axons detected in at the level of cervical spinal cord to be generally lower than that reported in our previous study using BDA (Liu et al., 2010). This difference could be attributed to bona fide difference in the number of axons in the cervical spinal cord, but a more likely reason is a technical one where BDA signal was detected with a much more sensitive method (using tyramide signal amplification).

Previous studies targeting various molecules to promote axonal growth have demonstrated that a combinatorial approach with CSPGs has synergistic/additive effects (Steinmetz et al., 2005; Tom et al., 2009; Karimi-Abdolrezaee et al., 2010; Alilain et 
al., 2011; García-Alías et al., 2011; Zhao and Fawcett, 2013; Zhao et al., 2013; Kanno et al., 2014). However, whether combined targeting of neuron intrinsic (PTEN) and extrinsic (CSPG) can have additive effects on supraspinal axonal growth has not been directly addressed. We observed significant enhancement in the degree of sprouting when both PTEN and CSPGs were inactivated simultaneously. This effect was close to the sum of the effects of each treatment alone, indicating an additive action of the two manipulations. Consistently, we previously observed that the onset of robust axonal regeneration in the injured mice optic nerve after PTEN deletion in adult retinal ganglion cells coincide with the onset of spontaneous decrease of CSPG level in the lesion, indicating the potent growth-inhibitory effect of CSPGs on the axons of PTEN deletedneurons (Park et al., 2008).

Although our data indicate that $\mathrm{mTOR}$ is involved in promoting sprouting induced by PTEN deletion or CSPG digestion, the extent to which these mechanisms are shared between these two cases is not clear and mTOR likely represents one of many different intracellular factors that could regulate axonal sprouting. In our study, we show that axon sprouting after ChABC treatment is reduced by rapamycin. This was unexpected because rapamycin was supposed to target neuron intrinsic mechanisms, whereas ChABC was supposed to target extrinsic mechanisms. However, we do not believe that $\mathrm{ChABC}$ is directly triggering increased mTOR activity in neurons. Rather, it seems that certain neurons have a basal level of mTOR-dependent growth capacity that enables them to sprout in response to CNS injury. This sprouting is enhanced further once extracellular inhibitory factors, such as CSPG, are removed. However, in the absence of this basal level of growth capacity, such as after rapamycin treatment, neurons are no longer capable of sprouting and thus do not respond to the removal of inhibitory molecules in the extracellular environment.

Collectively, our findings specify distinct $\mathrm{mTOR}$ requirement in postnatal and young adult CNS neurons for inducing axonal sprouting. Although the mechanisms underlying this disparity await future elucidation, our findings raise the possibility that the mechanisms allowing extensive sprouting in postnatal CNS neurons are rather distinct and more versatile compared with their young adult counterparts. We also demonstrate, for the time, that coinactivation of PTEN and CSPGs further improves collateral sprouting of CNS axons, indicating that ma-

E $100 \mu \mathrm{m}$.
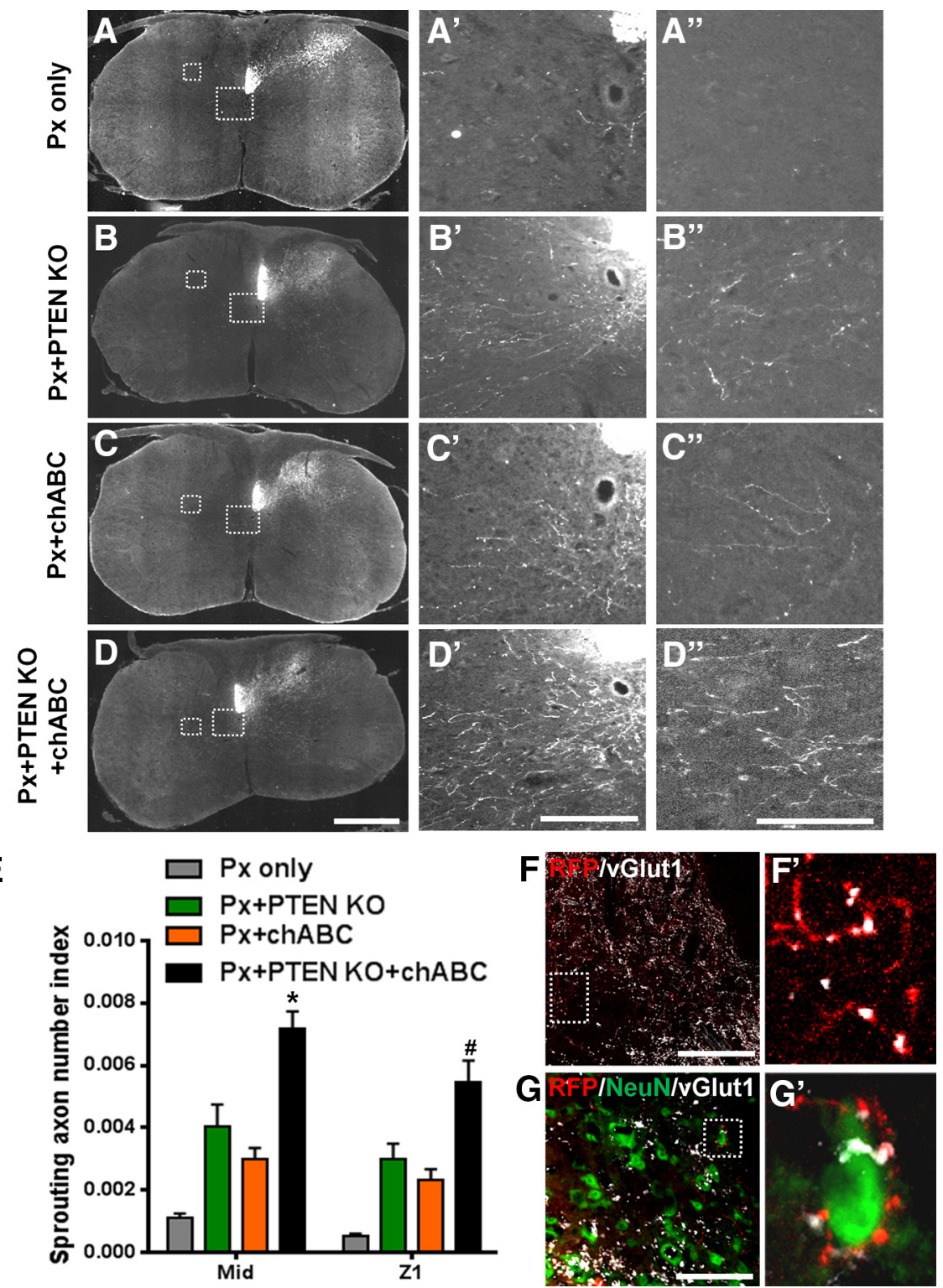

Figure 8. Combined modulation of PTEN/mTOR and CSPGs additively improves axonal sprouting. $\boldsymbol{A}-\boldsymbol{D}$, Representative C5 spinal cord coronal sections from animals receiving pyramidotomy only (Px only) and pyramidotomized animals receiving PTEN deletion (Px+PTEN K0), ChABC treatment (Px +ChABC), and PTEN deletion/ChABC treatment (PTEN KO/ChABC). In "Px only" and "Px+ChABC" animal groups, AAV-Cre was injected into Rosa-tdTomato mice, whereas in "Px+PTEN KO" and "Px+PTEN KO/ChABC" groups, AAV-Cre was injected into PTEN"ffRosa-tdTomato mice. "Px only" and "Px+PTEN $\mathrm{KO}$ "groups received intracerebroventricular delivery of saline. $\boldsymbol{E}$, Quantifications of crossing axons counted in different regions normalized against the numbers of tdTomato-labeled (ST axons ( $n=8-12 /$ group). $\boldsymbol{F}$, $\boldsymbol{G}$, Low-magnification coronal sections of the $C 5$ spinal cord showing gray matter of a pyramidotomized PTEN KO/ChABC mouse at 4 weeks after injury, stained for CST axons (RFP, red), vGlut1(white), and neurons (NeuN, green). $\boldsymbol{F}^{\prime}$, Enlargement of box in $\boldsymbol{F}$ showing ${\text { Vglut } 1{ }^{+} \text {RFP }^{+} \text {(tdTomato }}^{+}$) axons. $G^{\prime \prime}$, Enlargement of box in $\mathbf{G}^{\prime}$ showing Vglut ${ }^{+}{ }^{+}$RFP ${ }^{+}$terminals around a neuron. Asterisk indicates significantly different to "Px+PTEN KO" and "Px+ChABC" groups; $p<0.0001$. \#Indicates significantly different to "Px + PTEN KO" $(p<0.01)$ and "Px+ChABC" $(p<0.0001)$ groups; $n=8-12$ /group; two-way repeatedmeasures ANOVA followed by Bonferroni post-test. Error bars indicate SEM. Scale bars: $A-D, 500 \mu \mathrm{m} ; \boldsymbol{A}^{\prime}-\boldsymbol{D}^{\prime}, \boldsymbol{A}^{\prime \prime}-\boldsymbol{D}^{\prime \prime}, \boldsymbol{F}, \boldsymbol{G}$,

ture neurons receiving PTEN deletion possess confined ability to fully overcome environmental inhibition, and require simultaneous CSPG inactivation for a more robust effect. This requirement to target both neuron intrinsic and extrinsic mechanisms will be especially important in promoting functional recovery after more complex injuries, such as those to the spinal cord where there are multiple inhibitory barriers against axon regeneration. 


\section{References}

Abe N, Borson SH, Gambello MJ, Wang F, Cavalli V (2010) Mammalian target of rapamycin (mTOR) activation increases axonal growth capacity of injured peripheral nerves. J Biol Chem 285:28034-28043. CrossRef Medline

Alilain WJ, Horn KP, Hu H, Dick TE, Silver J (2011) Functional regeneration of respiratory pathways after spinal cord injury. Nature 475:196-200. CrossRef Medline

Barritt AW, Davies M, Marchand F, Hartley R, Grist J, Yip P, McMahon SB, Bradbury EJ (2006) Chondroitinase ABC promotes sprouting of intact and injured spinal systems after spinal cord injury. J Neurosci 26:1085610867. CrossRef Medline

Blackmore MG, Wang Z, Lerch JK, Motti D, Zhang YP, Shields CB, Lee JK, Goldberg JL, Lemmon VP, Bixby JL (2012) Kruppel-like Factor 7 engineered for transcriptional activation promotes axon regeneration in the adult corticospinal tract. Proc Natl Acad Sci U S A 109:7517-7522. CrossRef Medline

Bradbury EJ, Moon LD, Popat RJ, King VR, Bennett GS, Patel PN, Fawcett JW, McMahon SB (2002) Chondroitinase ABC promotes functional recovery after spinal cord injury. Nature 416:636-640. CrossRef Medline

Byrne AB, Walradt T, Gardner KE, Hubbert A, Reinke V, Hammarlund M (2014) Insulin/IGF1 signaling inhibits age-dependent axon regeneration. Neuron 81:561-573. CrossRef Medline

Cafferty WB, Yang SH, Duffy PJ, Li S, Strittmatter SM (2007) Functional axonal regeneration through astrocytic scar genetically modified to digest chondroitin sulfate proteoglycans. J Neurosci 27:2176-2185. CrossRef Medline

Chen HC, Fong TH, Hsu PW, Chiu WT (2013) Multifaceted effects of rapamycin on functional recovery after spinal cord injury in rats through autophagy promotion, anti-inflammation, and neuroprotection. J Surg Res 179:e203-210. CrossRef Medline

Christie KJ, Webber CA, Martinez JA, Singh B, Zochodne DW (2010) PTEN inhibition to facilitate intrinsic regenerative outgrowth of adult peripheral axons. J Neurosci 30:9306-9315. CrossRef Medline

Crespo D, Asher RA, Lin R, Rhodes KE, Fawcett JW (2007) How does chondroitinase promote functional recovery in the damaged CNS? Exp Neurol 206:159-171. CrossRef Medline

Davies SJ, Fitch MT, Memberg SP, Hall AK, Raisman G, Silver J (1997) Regeneration of adult axons in white matter tracts of the central nervous system. Nature 390:680-683. CrossRef Medline

Fouad K, Krajacic A, TetzlaffW (2011) Spinal cord injury and plasticity: opportunities and challenges. Brain Res Bull 84:337-342. CrossRef Medline

García-Alías G, Petrosyan HA, Schnell L, Horner PJ, Bowers WJ, Mendell LM, Fawcett JW, Arvanian VL (2011) Chondroitinase ABC combined with neurotrophin NT-3 secretion and NR2D expression promotes axonal plasticity and functional recovery in rats with lateral hemisection of the spinal cord. J Neurosci 31:17788-17799. CrossRef Medline

Harris NG, Mironova YA, Hovda DA, Sutton RL (2010) Chondroitinase $\mathrm{ABC}$ enhances pericontusion axonal sprouting but does not confer robust improvements in behavioral recovery. J Neurotrauma 27:1971-1982. CrossRef Medline

Jefferson SC, Tester NJ, Howland DR (2011) Chondroitinase ABC promotes recovery of adaptive limb movements and enhances axonal growth caudal to a spinal hemisection. J Neurosci 31:5710-5720. CrossRef Medline

Kanno H, Ozawa H, Sekiguchi A, Yamaya S, Tateda S, Yahata K, Itoi E (2012) The role of mTOR signaling pathway in spinal cord injury. Cell Cycle 11:3175-3179. CrossRef Medline

Kanno H, Pressman Y, Moody A, Berg R, Muir EM, Rogers JH, Ozawa H, Itoi E, Pearse DD, Bunge MB (2014) Combination of engineered Schwann cell grafts to secrete neurotrophin and chondroitinase promotes axonal regeneration and locomotion after spinal cord injury. J Neurosci 34: 1838-1855. CrossRef Medline

Karimi-Abdolrezaee S, Eftekharpour E, Wang J, Schut D, Fehlings MG (2010) Synergistic effects of transplanted adult neural stem/progenitor cells, chondroitinase, and growth factors promote functional repair and plasticity of the chronically injured spinal cord. J Neurosci 30:1657-1676. CrossRef Medline

Kwok JC, Afshari F, García-Alías G, Fawcett JW (2008) Proteoglycans in the central nervous system: plasticity, regeneration and their stimulation with chondroitinase ABC. Restor Neurol Neurosci 26:131-145. Medline

Lang C, Bradley PM, Jacobi A, Kerschensteiner M, Bareyre FM (2013) STAT3 promotes corticospinal remodelling and functional recovery after spinal cord injury. EMBO Rep 14:931-937. CrossRef Medline
Laplante M, Sabatini DM (2012) mTOR signaling in growth control and disease. Cell 149:274-293. CrossRef Medline

Law BK (2005) Rapamycin: an anti-cancer immunosuppressant? Crit Rev Oncol Hematol 56:47-60. CrossRef Medline

Lee H, McKeon RJ, Bellamkonda RV (2010a) Sustained delivery of thermostabilized chABC enhances axonal sprouting and functional recovery after spinal cord injury. Proc Natl Acad Sci U S A 107:3340-3345. CrossRef Medline

Lee JK, Geoffroy CG, Chan AF, Tolentino KE, Crawford MJ, Leal MA, Kang B, Zheng B (2010b) Assessing spinal axon regeneration and sprouting in Nogo-, MAG-, and OMgp-deficient mice. Neuron 66:663-670. CrossRef Medline

Leibinger M, Andreadaki A, Fischer D (2012) Role of mTOR in neuroprotection and axon regeneration after inflammatory stimulation. Neurobiol Dis 46:314-324. CrossRef Medline

Liu K, Lu Y, Lee JK, Samara R, Willenberg R, Sears-Kraxberger I, Tedeschi A, Park KK, Jin D, Cai B, Xu B, Connolly L, Steward O, Zheng B, He Z (2010) PTEN deletion enhances the regenerative ability of adult corticospinal neurons. Nat Neurosci 13:1075-1081. CrossRef Medline

Park KK, Liu K, Hu Y, Smith PD, Wang C, Cai B, Xu B, Connolly L, Kramvis I, Sahin M, He Z (2008) Promoting axon regeneration in the adult CNS by modulation of the PTEN/mTOR pathway. Science 322:963-966. CrossRef Medline

Schwab ME (2002) Increasing plasticity and functional recovery of the lesioned spinal cord. Prog Brain Res 137:351-359. CrossRef Medline

Starkey ML, Barritt AW, Yip PK, Davies M, Hamers FP, McMahon SB, Bradbury EJ (2005) Assessing behavioural function following a pyramidotomy lesion of the corticospinal tract in adult mice. Exp Neurol 195:524-539. CrossRef Medline

Starkey ML, Bartus K, Barritt AW, Bradbury EJ (2012) Chondroitinase ABC promotes compensatory sprouting of the intact corticospinal tract and recovery of forelimb function following unilateral pyramidotomy in adult mice. Eur J Neurosci 36:3665-3678. CrossRef Medline

Steinmetz MP, Horn KP, Tom VJ, Miller JH, Busch SA, Nair D, Silver DJ, Silver J (2005) Chronic enhancement of the intrinsic growth capacity of sensory neurons combined with the degradation of inhibitory proteoglycans allows functional regeneration of sensory axons through the dorsal root entry zone in the mammalian spinal cord. J Neurosci 25:8066-8076. CrossRef Medline

Sun F, Park KK, Belin S, Wang D, Lu T, Chen G, Zhang K, Yeung C, Feng G, Yankner BA, He Z (2011) Sustained axon regeneration induced by codeletion of PTEN and SOCS3. Nature 480:372-375. CrossRef Medline

Takeuchi K, Yoshioka N, Higa Onaga S, Watanabe Y, Miyata S, Wada Y, Kudo C, Okada M, Ohko K, Oda K, Sato T, Yokoyama M, Matsushita N, Nakamura M, Okano H, Sakimura K, Kawano H, Kitagawa H, Igarashi M (2013) Chondroitin sulphate $N$-acetylgalactosaminyl-transferase- 1 inhibits recovery from neural injury. Nat Commun 4:2740. CrossRef Medline

Tom VJ, Sandrow-Feinberg HR, Miller K, Santi L, Connors T, Lemay MA, Houlé JD (2009) Combining peripheral nerve grafts and chondroitinase promotes functional axonal regeneration in the chronically injured spinal cord. J Neurosci 29:14881-14890. CrossRef Medline

Weidner N, Tuszynski MH (2002) Spontaneous plasticity in the injured spinal cord-implications for repair strategies. Mol Psychiatry 7:9-11. CrossRef Medline

Yip PK, Wong LF, Sears TA, Yáñez-Muñoz RJ, McMahon SB (2010) Cortical overexpression of neuronal calcium sensor-1 induces functional plasticity in spinal cord following unilateral pyramidal tract injury in rat. PLoS Biol 8:e1000399. CrossRef Medline

Zhao RR, Fawcett JW (2013) Combination treatment with chondroitinase ABC in spinal cord injury: breaking the barrier. Neurosci Bull 29:477483. CrossRef Medline

Zhao RR, Muir EM, Alves JN, Rickman H, Allan AY, Kwok JC, Roet KC, Verhaagen J, Schneider BL, Bensadoun JC, Ahmed SG, Yáñez-Muñoz RJ, Keynes RJ, Fawcett JW, Rogers JH (2011) Lentiviral vectors express chondroitinase $\mathrm{ABC}$ in cortical projections and promote sprouting of injured corticospinal axons. J Neurosci Methods 201:228-238. CrossRef Medline

Zhao RR, Andrews MR, Wang D, Warren P, Gullo M, Schnell L, Schwab ME, Fawcett JW (2013) Combination treatment with anti-Nogo-A and chondroitinase $\mathrm{ABC}$ is more effective than single treatments at enhancing functional recovery after spinal cord injury. Eur J Neurosci 38:29462961. CrossRef Medline 